\title{
Hygro-thermal performance of wooden beam ends: experimental investigations of uninsulated and internally insulated brick wall
}

\author{
Pavel Kopecký1, ${ }^{1,}$, Kamil Staněk ${ }^{1}$, and Jan Tywoniak ${ }^{1}$ \\ ${ }^{1}$ University Centre for Energy Efficient Buildings, Třinecká 1024, 27343 Buštěhrad, Czech Republic
}

\begin{abstract}
Wooden floors were traditionally used in brick apartment houses built at the turn of 20th century in many European cities. Thermal renovation of such houses often involves thermal insulation at interior side of external walls. Internal insulation makes microclimate in the vicinity of wooden beam ends colder and more humid. The real-scale experiment involving a part of wooden floor connected to a $30 \mathrm{~cm}$ thick masonry wall was monitored for two consecutive years. Measured data were used to compare microclimate in sealed and open joist pockets. Joist pockets were either placed in the masonry wall with plaster on both sides or placed in the same masonry wall insulated on the interior side (vapour open thermal insulation system). The measured results indicate that the sealing tape alone is not sufficient to keep the relative humidity in joist pockets below $85 \%$ in cold climate and under high internal moisture load. The paper concludes that reasonable trade-off between thermal efficiency, thermal comfort and moisture safety is difficult to reach for masonry with internal insulation and wooden floors. Sealing provisions complemented by tempering of joist pockets are considered as two key technical measures for reliable hygro-thermal performance of wooden beam ends in full-brick masonry with interior thermal insulation in cold temperate climate.
\end{abstract}

\section{Introduction}

Approximately, $36 \%$ of the Czech population live in buildings built before 1945 [1]. These buildings are typically 4 to 5 floors high with cold attic under pitched roof. The thickness of the masonry usually ranges from 75 to $45 \mathrm{~cm}$, with half-brick decrement per one floor. Masonry with thickness of $30 \mathrm{~cm}$ could be also found, e.g. in gables. Masonry is built from full red bricks and is usually plastered on both sides. Thermal transmittance of the wall is much higher than the current technical standards require. The external plaster often contains decorative patterns with architectural and cultural value. The thermal insulation placed on the external side of the wall is not permitted or technically feasible and majority of such existing buildings is still in its original condition.

Many of old apartment houses contain wooden floors. Wooden beams are usually embedded in masonry pockets with depth of $15 \mathrm{~cm}$ or slightly more. The depth of pockets and the overall thickness of the wall ensure that wooden beam ends are located on the warmer side of the wall. Moreover, the distance of $30 \mathrm{~cm}$ or more between the external surface and the internal surface of the pockets is sufficient for buffering liquid water during rain episodes.

It was recommended by preceding building laws to put a plate of hardwood under the wooden beam end. It was also recommended to provide at least $2 \mathrm{~cm}$ thick air gap between the pocket and wood. As proven by the long-term experience, wooden beam ends in bare-brick walls did not decay in climatic conditions of middle Europe. Decayed wood is occasionally being found at the beams that carry metal anchors protruding into the wall (typically present in every 4 th pocket).

Hygro-thermal performance of the wall and joist pockets is worsened when the layer of thermal insulation is added on the interior side of masonry wall, (see Figure 1).
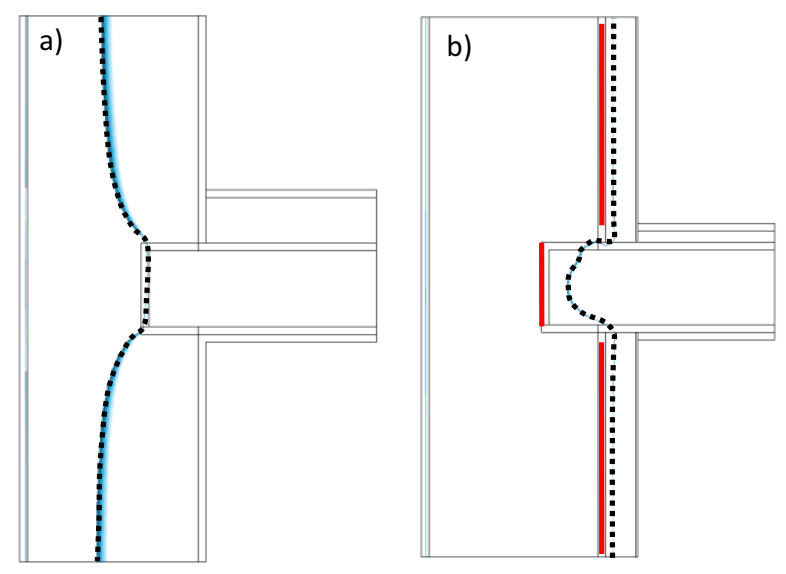

Fig. 1. Contour of $85 \%$ relative humidity (black dotted line) and condensation zone (red line) as calculated in [2] for constant boundary conditions $21^{\circ} \mathrm{C} / 50 \%$ and $-1{ }^{\circ} \mathrm{C} / 84 \%$. a) uninsulated masonry $(45 \mathrm{~cm})$ with original floor, b) internally insulated wall with new floor, $8 \mathrm{~cm}$ thick vapour open system with plaster, unsealed joist pocket.

\footnotetext{
* Corresponding author: pavel.kopecky@,fsv.cvut.cz
} 
If the wall is insulated on the interior side, wooden beam ends are no more located in the warm part of the wall. The layer of insulation decreases heat flow through the wall and elevates temperature of the internal surface. It therefore decreases space heating needs and improves thermal comfort of inhabitants. At the same time, it could introduce new thermal bridges (e.g. wall-to-floor junction). It also increases the risk of water vapor condensation at the interface between masonry and thermal insulation and in the joist pockets. Consequently, wooden beam ends could be located in unfavourable environmental conditions during cold part of the year (see Figure 1). Long-term exposure of wooden beam ends to high humidity could lead to their decay.

The microclimate in joist pockets represents a complex hygro-thermal problem involving $3 \mathrm{D}$ dynamic heat and moisture transfer. It involves several loads, transport and retention processes. The processes take place in materials and in boundary layers adjacent to surfaces of materials. The complexity associated with porous system of wood, e.g. variability of properties in three principal anatomical directions, shrinkage and swelling behaviour, makes it even more complicated.

Previous experimental studies [e.g. 3, 4] shown that microclimate in joist pockets is sensitive to convective coupling between internal environment and joist pockets. To prevent this, a sealing tape or similar measure can be used. Its position and the length of its overlap on the masonry, and on the sides of the beam, respectively, could be of importance. On the other hand, airtight sealing of joist pockets might lower drying of moisture from joist pockets into internal environment during warmer months of the year.

To study various cases of wooden beam ends, longtime real-scale experiment exposed to ambient boundary conditions of south-west façade was built in University Center for Energy Efficient Buildings (UCEEB) of the Czech Technical University in Prague. Boundary conditions, temperatures, relative humidity, moisture content in wood, and heat fluxes, are recorded. The experiment is a follow-up to an experiment carried out in time period 2015-2018 [5]. The new experiment compares joist pockets in uninsulated masonry wall (thickness of $30 \mathrm{~cm}$, plastered on both sides) with joist pockets in masonry wall insulated on interior side.

\section{Materials and methods}

\subsection{Experimental cases}

The experiment was designed to enable a side-by-side comparison of joist pockets in uninsulated brick masonry and joist pockets in masonry with interior insulation. The test facade, with dimensions 3.0 by $3.2 \mathrm{~m}$, is located in the south-west wall of a climatic room. The test facade is exposed to real weather conditions. As the wind directions on site is predominantly south-west, the test facade is naturally loaded by wind driven rain. The internal environment of the climatic room is controlled by HVAC unit.
The experiment was built in May 2018 on the basis of the previous wooden beam end experiment [5]. The material layers of the original wooden floors and sealing tapes at the joist pockets were dismounted. The layers of insulation system were stripped off as well. Wooden beam ends were kept in masonry pockets with some exceptions due to visual inspection and sampling for laboratory investigations of molds (see [5]). The wooden floors were then re-assembled. The head of the floor is distanced by $120 \mathrm{~cm}$ from the surface of the masonry and is sealed by a plastic foil.

Two different walls with two wooden floors were built (see Figure 2). The composition of walls and wooden floors are defined in Table 1 . The half of the test facade is uninsulated. The other half of the test facade is insulated from interior using vapor open insulation system. Boards consisting of soft and hard wooden fiber $(2 \times 40 \mathrm{~mm})$ are attached to internal surface of masonry by plastic anchors with metal screws. No adhesive between the insulation and the masonry is applied. Thermal insulation is not placed between wooden beams of the first floor. The second floor of the internally insulated wall is assembled with continuous thermal insulation in between the wooden beam. See [5] for more information about the insulation system.

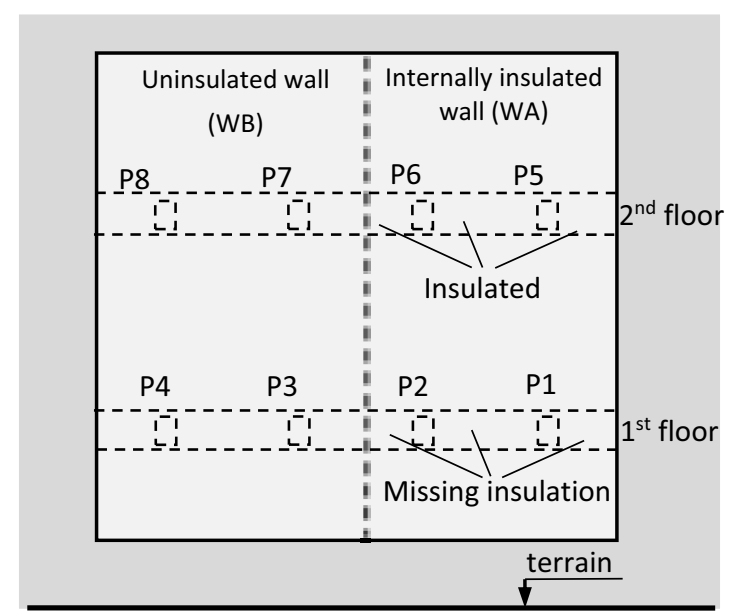

Fig. 2. Outside view on the test façade with position of joist pockets.

The variants of joist pockets are defined in Table 2 . Joist pockets are either sealed by tape or left open. The tape was attached on the surface of the masonry. The overlap of the tape is approximately $5 \mathrm{~cm}$. Four wooden beam ends were wrapped in vapour tight plastic foil up to the distance of $30 \mathrm{~cm}$ from the surface of the masonry. Wrapping of wooden beam end in plastic foil should not be understood as a technical measure for improvement of microclimate in joist pockets. Such treatment is used in the experiment to obtain better insight on the impact of wooden body on microclimate in joist pockets (effects of moisture retention and vapour transport in wood). 
Table 1. Composition of building components (from interior).

\begin{tabular}{|c|c|c|}
\hline Component & Material & $\begin{array}{c}d \\
{[\mathrm{~mm}]}\end{array}$ \\
\hline \multirow{4}{*}{$\begin{array}{l}\text { Uninsulated } \\
\text { wall (WB) }\end{array}$} & Lime-cement plaster & $<15$ \\
\hline & Brick masonry & 300 \\
\hline & Lime-cement plaster & $<15$ \\
\hline & Fine coat & 5 \\
\hline \multirow{5}{*}{$\begin{array}{c}\text { Internally } \\
\text { insulated } \\
\text { wall (WA) }\end{array}$} & Plaster & 5 \\
\hline & Wood fiber insulation & 80 \\
\hline & Brick masonry & 300 \\
\hline & Lime-cement plaster & $<15$ \\
\hline & Fine coat & 5 \\
\hline \multirow{7}{*}{$\begin{array}{l}\text { Wooden } \\
\text { floors (from } \\
\text { bottom to } \\
\text { top) }\end{array}$} & Acrylic paint & - \\
\hline & Gypsum board & 12.5 \\
\hline & Wooden planks & 20 \\
\hline & $\begin{array}{l}\text { Closed air gap } \\
\text { between beams }\end{array}$ & 200 \\
\hline & Wooden planks & 20 \\
\hline & Mineral wool & 30 \\
\hline & OSB & 18 \\
\hline
\end{tabular}

Table 2. Definition of joist pockets.

\begin{tabular}{|c|c|c|c|}
\hline Pocket & $\begin{array}{c}\text { Thermal } \\
\text { insulation }\end{array}$ & $\begin{array}{c}\text { Sealing } \\
\text { tape }\end{array}$ & $\begin{array}{c}\text { Beam end packed } \\
\text { in plastic foil }\end{array}$ \\
\hline P1 & Yes & No & Yes \\
\hline P2 & Yes & No & No \\
\hline P3 & No & No & No \\
\hline P4 & No & No & Yes \\
\hline P5 & Yes & Yes & Yes \\
\hline P6 & Yes & Yes & No \\
\hline P7 & No & Yes & No \\
\hline P8 & No & Yes & Yes \\
\hline
\end{tabular}

\subsection{Position of measurement sensors}

Positions of the sensors are shown in Figure 3. Placement of sensors and type of sensors are similar with the preceding experiment [5]. Some new sensor positions were introduced. $\mathrm{T}+\mathrm{RH}$ sensors were buried in the external plaster and under the internal plaster. These sensors were wrapped in vapour permeable foil (protection against liquid water). Additional $\mathrm{T}+\mathrm{RH}$ sensors were mounted on both sides of the sealing tape in the upper part of two selected wooden beams (joist pockets $\mathrm{P} 6$ and $\mathrm{P} 7$ ).

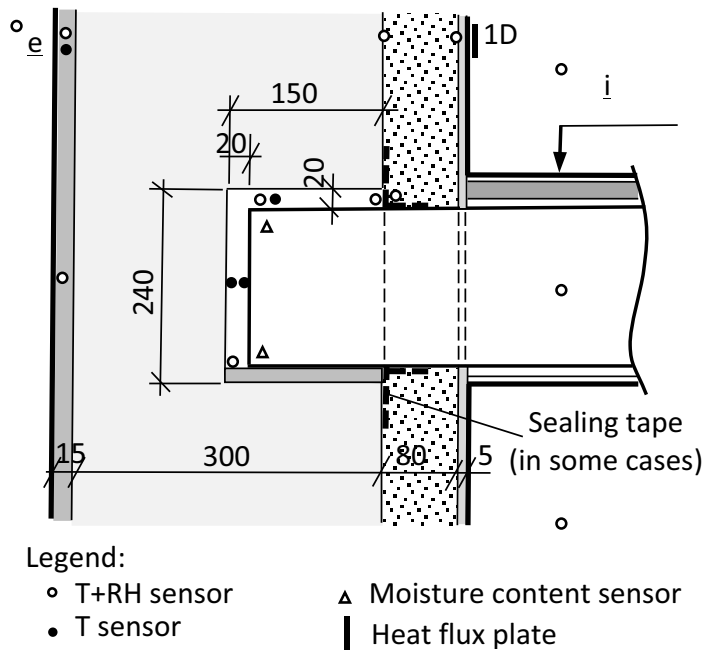

Fig. 3. Position of measurement sensors.

\subsection{Diary of the experiment}

The experiment was built in May 2018. The data acquisition system is active since the beginning of June 2018. The first warm season was intended for drying-out of built-in moisture. Temperature and relative humidity of indoor air were kept constant during cold seasons by applying set points $23{ }^{\circ} \mathrm{C}$ and $60 \%$. Set points were active between 10 October 2018 and 16 May 2019, and since 5 November 2019, respectively. Unfortunately, the humidifier was influenced by mineral deposits (calcite), and the relative humidity of internal air dropped to $50 \%$ in the coldest days of January 2019. Deposits in humidifier were cleaned in October 2019 so humidification should work properly in the current cold season 2019-2020.

The conditions in climatic room were also influenced by works on another experiment in May and June 2019, when the HVAC unit was switched off (16 May $2019-$ 9 July 2019). Scaffolding was built in front of the test façade till 27 June 2019 (shading effect). HVAC was switched on again on 9 July 2019 (cooling to $23{ }^{\circ} \mathrm{C}$, no dehumidification).

\section{Results}

The data are recorded in time step of one minute. Calculated daily mean values of temperature and relative humidity are depicted in Figure 4 - Figure 10.

\subsection{Measured data in walls}

The data measured in the cross section of both walls (i.e. where 1D heat and moisture transfer is expected), are depicted in Figure 4.

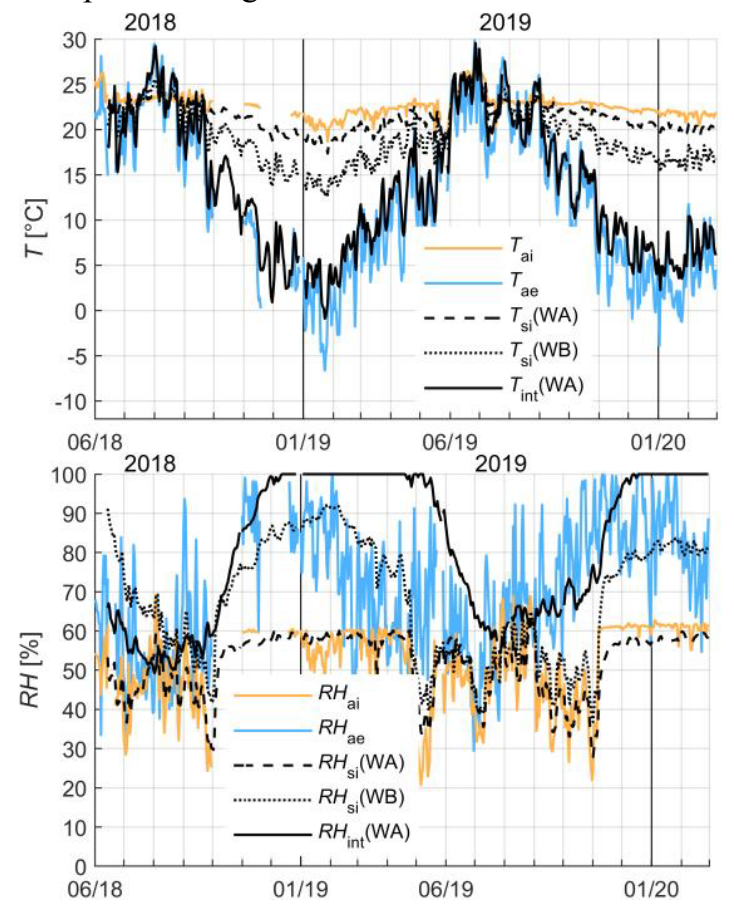

Fig. 4. Measured data (WA and WB) - daily averages of temperature and relative humidity, subscripts used in figures: ae - external air, ai - internal air, si - internal surface, int interface between the masonry and thermal insulation. 


\subsection{Measured data in joist pockets}

Daily mean values of temperature and relative humidity in joist pockets (bottom $\mathrm{T}+\mathrm{RH}$ sensor) together with boundary conditions are depicted in Figure 5 (temperature in selected pockets), Figure 6 (joist pockets in upper floor), Figure 7 (joist pockets in bottom floor) and Figure 8 (comparison between floors). Temperature

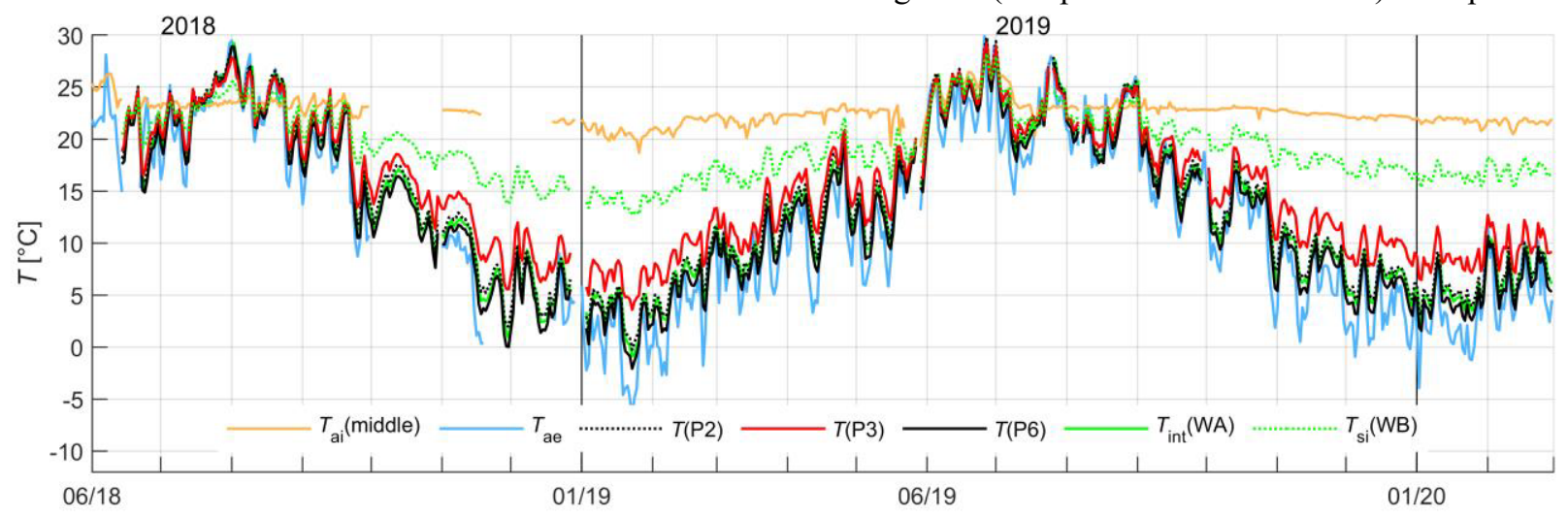

Fig. 5. Measured temperature in joist pockets.

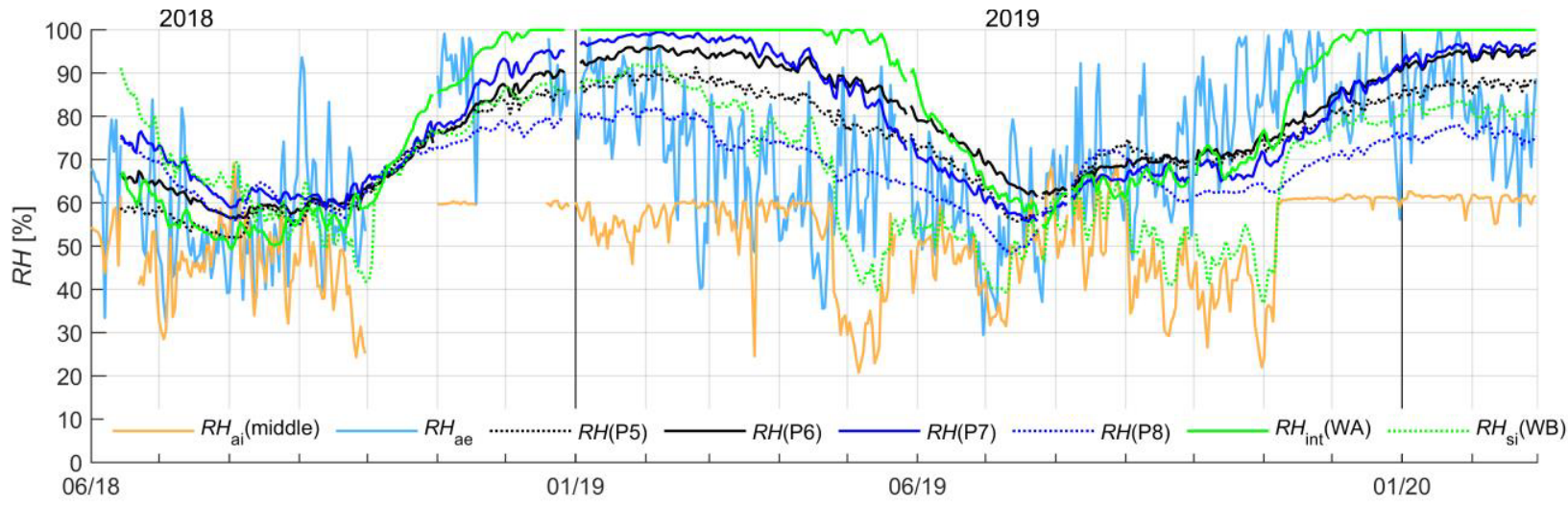

Fig. 6. Measured relative humidity (comparison of joist pockets placed in the upper floor).

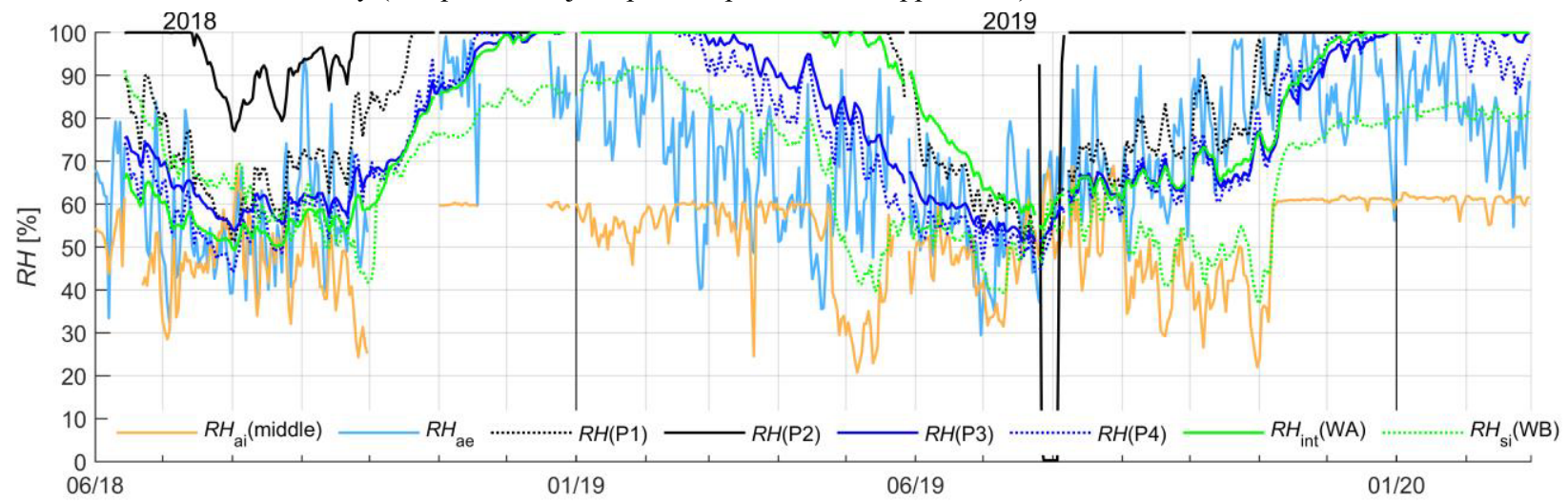

Fig.7. Measured relative humidity (comparison of joist pockets placed in the bottom floor).

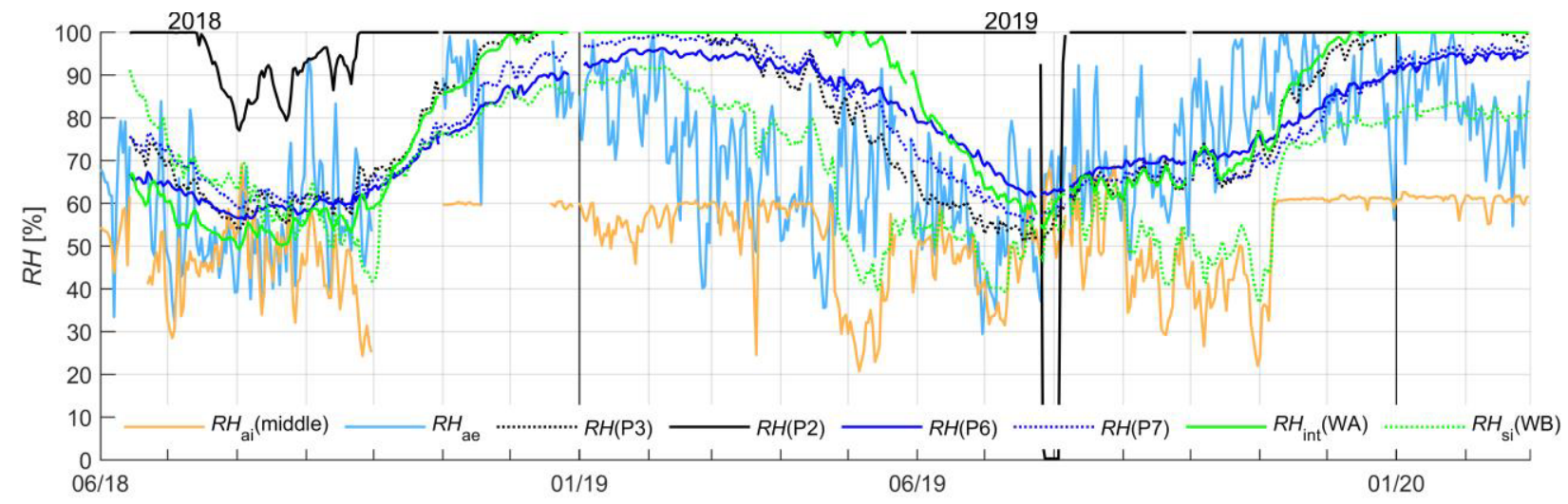

Fig. 8. Measured relative humidity (comparison between floors). 
and relative humidity in joist pockets are complemented by relative humidity measured on the interface between masonry and interior insulation and on the internal surface of bare-brick wall. Comparison between joist pockets in $2^{\text {nd }}$ floor and $1^{\text {st }}$ floor has to be performed cautiously due to uneven internal boundary conditions. Air close to the upper floor was warmer and more humid than the air above the ground (below $1^{\text {st }}$ floor).

\section{Discussion}

Temperature in joist pockets placed in uninsulated masonry was higher than temperature in joist pockets placed in masonry with interior insulation (by about $4{ }^{\circ} \mathrm{C}$ if P3 is compared with $\mathrm{P} 2$, by about $6{ }^{\circ} \mathrm{C}$ if $\mathrm{P} 3$ is compared with P6, see Figure 5). In spite of higher temperatures, open joist pockets $\mathrm{P} 3$ and $\mathrm{P} 4$ placed in uninsulated masonry reached $100 \% \mathrm{RH}$ in cold season 2018-2019 (see Figure 7).

Temperature in open joist pockets placed in masonry with interior insulation (joist pockets $\mathrm{P} 1$ and $\mathrm{P} 2$ ) was by about $2{ }^{\circ} \mathrm{C}$ higher than temperature in joist pocket $\mathrm{P} 6$ or P5 (see Figure 5). Missing thermal insulation between wooden beams and convective heat exchange between floor cavity and open joist pockets are responsible for such temperature difference. In spite of higher temperatures, open joist pockets $\mathrm{P} 1$ and $\mathrm{P} 2$ placed in masonry with interior insulation maintained $100 \% \mathrm{RH}$ from early autumn to late spring. RH sensor in joist pocket $\mathrm{P} 2$ probably gives incorrect values. Nonetheless, its malfunction can be related to high humidity in joist pocket P2.

Sealed joist pockets P5 and P6 are compared with open joist pockets P1 and P2 (P1 - P5, P2 - P6). Sealed joist pockets $\mathrm{P} 7$ and $\mathrm{P} 8$ are compared with open joist pockets P3 and P4 (P3 - P7, P4 - P8). Sealing by tape led to visible decrease of RH (see P2 and P6 in Figure 7, respectively P3 and P7 in Figure 8). RH is however still far beyond what is considered to be moisture safe value.

Sealing by tape limited drying of joist pockets in warm season to some extent. Lower RH over cold season is balanced by higher RH in warm season. Since the overlap of sealing tape on masonry and wooden beam is only $5-10 \mathrm{~cm}$, and insulation system is vapor open, the reduction of drying ability does not seem to be critical.

Comparison of "beam-in-foil" cases with standard cases (i.e. compare P5 - P6 resp. P7 - P8 in Figure 6, and compare P1 - P2 resp. P3 - P4 in Figure 7) show visible difference of $\mathrm{RH}$. The cases in which the wooden beam end was wrapped in foil reached lower RH in cold season. Low difference of RH could indicate that the influence of wooden beam end on microclimate in joist pockets is not dominant factor in such a case. Higher difference of $\mathrm{RH}$ could indicate that the influence of wooden beam end on microclimate of joist pockets is strong contributor in such a case. Vapor diffusion resistance of the floor (material layers above and below the wooden beam) should be increased to avoid entrance of vapor from the internal environment into wooden beam which is permeable for water vapor in longitudinal direction.
The measured results indicate that the sealing tape alone is not sufficient to keep the relative humidity in joist pockets below $85 \%$ in cold climate and under high internal moisture load $\left(23{ }^{\circ} \mathrm{C}, 60 \% \mathrm{RH}\right)$. Sealing of joist pockets together with tempering, either performed passively [6] or actively [7], could be two necessary technical measures for moisture safety of joist pockets. For instance, suitable metal profiles could be used as strengthening and also conducting elements bringing heat from internal environment into the joist pocket. Moreover, if vertical loads are introduced in the masonry by such metal elements, the wooden beam end can be removed from the joist pocket. The rest of beam is then located in the internal environment which seldom exceeds $60 \%$ RH. Such refurbishment is technically feasible yet difficult if should be achieved without disturbance of flats below the floor.

\section{Conclusions}

Open joist pockets reached very high relative humidity for both test walls (30 cm thick uninsulated masonry and masonry with vapor open thermal insulation system). Sealing led to improvement of hygric performance in the joist pockets. However, sealing alone was not sufficient to keep the relative humidity below $85 \%$.

Microclimate observed in joist pockets during the experiment was far beyond what is considered as moisture safe in engineering practice $(\mathrm{RH}<80 \%)$. Trade-off between thermal efficiency, thermal comfort and moisture safety is very difficult to reach for masonry with internal insulation and wooden floors. Welldesigned real-scale experiments, calculation studies and pilot installations are necessary to verify possible technical measures.

Acknowledgement: This work has been supported by the project GACR 20-12941S. The authors are very grateful to technical staff members Radim Havlíček and Jan Vítovec for construction works on the experiments.

\section{References}

1. Czech Statistical Office. Census 2011. Available online at: https://www.czso.cz (in Czech).

2. Software AREA2017 2D (EDU version).

3. E. Vereecken, S. Roels, Building and Environment 148, (2017).

4. P. Wegerer, T. Bednar, Energy Procedia, 132, (2017).

5. P. Kopecký et al., Journal of Building Physics 43, (2019).

6. M. Dragoun, Diploma thesis, available at : https://dspace.cvut.cz/handle/10467/74564 (in Czech), (2018).

7. P. Wegerer, T. Bednar, Improving Durability of Wooden Beam Bearings in Inside Insulated Walls by Tempering the Beam's Heads Conference: 7th International Building Physics Conference, Syracuse, (2018). 